\title{
Impact of Intervention on Awareness of Biomedical Waste Disposal Among Medical Students
}

\author{
Dhananjay Shrikant kotasthane*, Vaishali Dhananjay kotasthane, Shanmugasamy K and Ancy A \\ Department of Pathology, Mahatma Gandhi Medical College and Research Institute, Pillaiyarkuppam, Pondicherry, India
}

\begin{abstract}
Background: The proper management of biomedical waste has become a worldwide humanitarian topic today. Hazards of poor management of biomedical waste have aroused the concern world over, especially in the light of its far-reaching effects on human, health and the environment. With this milieu, this interventional study was carried out on medical students aimed at assessing and creating the awareness of knowledge of Biomedical Waste Management (BMWM) among Second year MBBS Students.

Methods: Multiple-choice-Question(MCQ) based Questionnaire was administered to the students. This was followed by a lecture on Biomedical Waste Management.The same MCQ based Questionnaire was administered to the students immediately after the lecture and after one month. The questions in the test were based on Four domains-"Existence of Biomedical Waste rules", "Categories of Waste", "Different colour codes used" and "Waste disposal methods" Mean scores were calculated for the entire tests as well as for these domains.

Results: Mean scores in pre-lecture test indicated that awareness of Biomedical Waste Management amongst medical students was quite low. Mean scores were higher in post lecture test and post one month test, indicating that the knowledge of the various aspects of biomedical waste management significantly improved after the lecture conducted by the investigator of the study However, the knowledge did not sustain after one month, though it was still higher than the original baseline level. Friedman test and Wilcoxon signed rank tests were used to prove the statistical significance.
\end{abstract}

Conclusion: This study shows that early sensitisation about BMWM in Second MBBS students who are future doctors will improve awareness of BMWM. Repeated sensitisation is needed for the knowledge levels to sustain.

\section{Keywords: Biomedical waste, Medical students, Awareness}

\section{Introduction}

Hospital waste management is a global problem of immediate concern, due to rapid increase in the hospital acquired infection both by the general public as well as the health personnel. ${ }^{[1]}$

Healthcare facilities create waste that may hazardous to health. The importance of segregation of Hazardous Biomedical Waste and general waste is that only $10 \%$ to $25 \%$ of waste generated in health facilities is hazardous. Failure of this vital step of segregation turns nonhazardous waste into hazardous. Segregation also enables thosewho handle the containers outside the hospitalwards to identify and treat them appropriately. About 0.5 to $2.0 \mathrm{~kg}$ per bed per day hospital waste is generated in India. ${ }^{[2]}$ Hospital waste is a potential health hazard to the health care workers, public, flora and fauna of the area. ${ }^{[3]}$

The BMW invites flies, insects, rodents, cats and dogs that are responsible for the spread of communicable diseases. Rag pickers in the hospital, sorting out the garbage are at a risk of getting various infections. The recycling of disposable syringes, needles, IV sets and other article like glass bottles without proper sterilization are responsible for Hepatitis, HIV, and other viral diseases. It becomes primary responsibility of Health administrators to manage hospital waste in most safe and eco-friendly manner. ${ }^{[3]}$

Benefits of BMWM results in cleaner and healthier surroundings, reduction in the incidence of hospital acquired and general infectionsand preventsreuse and repackaging of infectious disposables. ${ }^{[3]}$ With this milieu, this study was undertaken to assess and create the awareness with respect to healthcare waste management among the Medical students.

\section{Material and Methods}

This interventional study was conducted after getting approval of Institutional Human Ethical Committee and taking informed consent of second MBBS students.

The students of second year were administered prevalidated MCQ test of sixteen questions on BMWM.The questions framed were based on Domains- "Existence of Biomedical waste rules", "Categories of waste", "Different colour codes used in biomedical waste management" and "Waste disposal methods" 
A short lecture on Biomedical Waste Management was delivered to the students by an investigator in this study. The same MCQ test was administered after the lecture and after one month. The pre lecture, post lecture and post one month response given was assessed in the overall test and Mean scores were calculated. Also the number of participants were categorised based on performance, both in pre and post test under following headings-a.less than $50 \%$,b.between 50 to $75 \%$,c.more than $75 \%$.

Mean scores and the results in the tests were compared. Friedman test and Wilcoxan signed Rank test was used to calculate statistical significance between pre lecture test and post lecture test and between post lecture test and post one month test. $\mathrm{P}$ value less than 0.05 was considered as statistically significant.

\section{Results}

Total 143 students were present, when this research project was carried out in the class. They volunteered to participated in the research Project.Mean scores were calculated and also the results in pre lecture test,post lecture test and post lecture one month test were categorised into 3 categories-Students scoring less than $50 \%, 50$ to $75 \%$ and more than $75 \%$ in the pre lecture, post -lecture and post one month assessment. These assessments were carried out for overall results and also separately for each of the above mentioned domains.

As shown in Tables 1,2,3,4,5 mean scores in the post lecture test and post one month test were more than the pre-lecture test.Similar findings are seen in the percentage scored by the students as shown in figures $1,2,3,4,5$. P value calculated using Friedman test (Tables 1 to 5) showed that difference in scores of post one month test and post lecture as well as pre lecture test was statistically significant for the entire test and also for individual domains.

Mean scores in the post lecture and post one month test were higher than the pre-lecture test. As shown in Table 6, p value calculated using Wilcoxon Signed Ranks test demonstrated that differences between prelecture test and post lecture test was statistically significant for overall test as well as individual domains. However, the mean scores in post one month test were lower as compared to post lecture test, though they were still higher than the baseline level of pre lecture test.

$P$ value calculated using Wilcoxan Signed Ranks test for difference between pre lecture test and post one month test was statistically significant for the overall test and also for Domain 2 i.e 'Categories of biomedical waste'. However, $\mathrm{p}$ value for difference in pre lecture and post one month test was not significant for Domain 1(existence of biomedical rules), Domain 3(Different colour codes used) and Domain 4 (Waste disposal methods). This proves that the knowledge of the students improved significantly immediately after the lecture but did not sustain after one month in all domains of knowledge, though the levels were still higher than the baseline level. This indicates the need for repeated sensitisation.

Table 1: Friedman test for overall test

\begin{tabular}{|c|c|c|c|c|c|}
\hline Overall & Pre & Po1 & Po2 & Friedman Test & p-value \\
\hline Mean & 6.64 & 11.92 & 8.06 & \multirow{5}{*}{164.888} & \multirow{5}{*}{$<0.0001$} \\
\hline Median & 7 & 12 & 8 & & \\
\hline Std. Deviation & 2.064 & 2.512 & 2.948 & & \\
\hline Minimum & 2 & 3 & 1 & & \\
\hline Maximum & 10 & 16 & 13 & & \\
\hline
\end{tabular}

Pre=prelecture, Po $1=$ post lecture,Po 2=post lecture one month

Table 2: Friedman test for Domain(D1)“Existence of biomedical waste management rules”

\begin{tabular}{|c|c|c|c|c|c|}
\hline D1 & Pre & Po1 & Po2 & Friedman Test & $p$-value \\
\hline Mean & 1.99 & 3.44 & 2.47 & \multirow[t]{5}{*}{120.766} & \multirow[t]{5}{*}{$<0.0001$} \\
\hline Median & 2 & 4 & 3 & & \\
\hline Std. Deviation & 0.915 & 0.853 & 0.948 & & \\
\hline Minimum & 0 & 1 & 0 & & \\
\hline Maximum & 4 & 4 & 4 & & \\
\hline
\end{tabular}


Table 3:Friedman test for Domain (D2) "categories of Biomedical waste"

\begin{tabular}{|c|c|c|c|c|c|}
\hline D2 & Pre & Po1 & Po2 & Friedman Test & p-value \\
\hline Mean & 1.36 & 3.32 & 2.1 & \multirow[t]{5}{*}{137.753} & \multirow[t]{5}{*}{$<0.0001$} \\
\hline Median & 1 & 4 & 2 & & \\
\hline Std. Deviation & 0.93 & 0.969 & 1.241 & & \\
\hline Minimum & 0 & 0 & 0 & & \\
\hline Maximum & 4 & 4 & 4 & & \\
\hline
\end{tabular}

Table 4:Friedman test for Domain (D3)“Different colour codes used”

\begin{tabular}{|c|c|c|c|c|c|}
\hline D3 & Pre & Po1 & Po2 & Friedman Test & p-value \\
\hline Mean & 1.66 & 2.72 & 1.69 & \multirow{5}{*}{70.228} & \multirow{5}{*}{$<0.0001$} \\
\hline Median & 2 & 3 & 2 & & \\
\hline Std. Deviation & 0.912 & 1.051 & 1.09 & & \\
\hline Minimum & 0 & 0 & 0 & & \\
\hline Maximum & 4 & 4 & 3 & & \\
\hline
\end{tabular}

Table 5:Friedman test for Domain(D4)“Waste disposal methods”

\begin{tabular}{|c|c|c|c|c|c|}
\hline D4 & Pre & Po1 & Po2 & Friedman Test & \\
\cline { 1 - 3 } Mean & 1.63 & 2.44 & 1.81 & \multirow{2}{*}{54.814} \\
Median & 2 & 3 & 2 & $<0.0001$ \\
Std. Deviation & 0.811 & 0.844 & 1.007 & \\
\hline Minimum & 0 & 0 & 0 & \\
\hline
\end{tabular}

Table 6:Wicoxan Signed Ranks test

\begin{tabular}{|c|c|c|c|}
\hline DOM = ALL & Po1 - Pre & Po2_level - Pre & Po2_level - Po1 \\
\hline Wilcoxon Signed Ranks Test & -10.022 & -10.361 & -10.400 \\
\hline $\mathrm{p}$-value & 0.000 & 0.000 & 0.000 \\
\hline $\mathrm{DOM}=\mathrm{D} 1$ & Po1 - Pre & Po2_level - Pre & Po2_level - Po1 \\
\hline Wilcoxon Signed Ranks Test & -9.060 & -0.761 & -9.808 \\
\hline p-value & 0.000 & 0.446 & 0.000 \\
\hline $\mathrm{DOM}=\mathrm{D} 2$ & Po1 - Pre & Po2_level - Pre & Po2_level - Po1 \\
\hline Wilcoxon Signed Ranks Test & -9.747 & -4.358 & -9.010 \\
\hline p-value & 0.000 & 0.000 & 0.000 \\
\hline $\mathrm{DOM}=\mathrm{D} 3$ & Po1 - Pre & Po2_level - Pre & Po2_level - Po1 \\
\hline Wilcoxon Signed Ranks Test & -7.030 & -1.433 & -8.368 \\
\hline p-value & 0.000 & 0.152 & 0.000 \\
\hline $\mathrm{DOM}=\mathrm{D} 4$ & Po1 - Pre & Po2_level - Pre & Po2_level - Po1 \\
\hline Wilcoxon Signed Ranks Test & -6.719 & -0.492 & -7.968 \\
\hline$p$-value & 0.000 & 0.622 & 0.000 \\
\hline
\end{tabular}




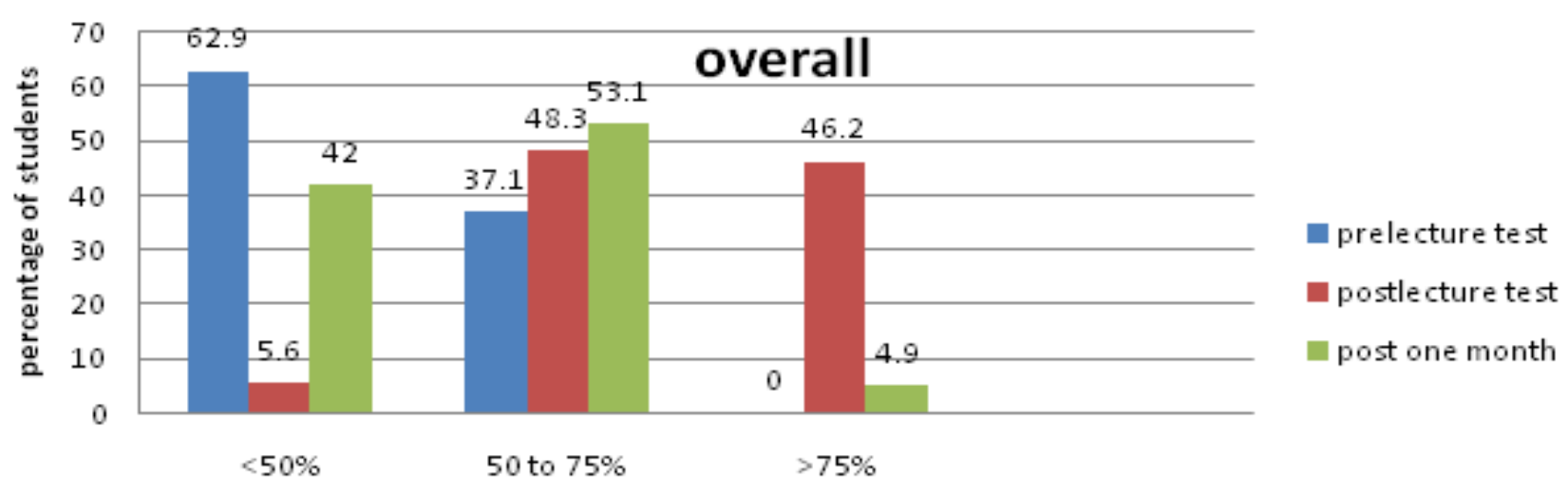

Students performance

Fig. 1: Assessment of the Medical students' overall knowledge in pre lecture, post lecture test and post one month test.

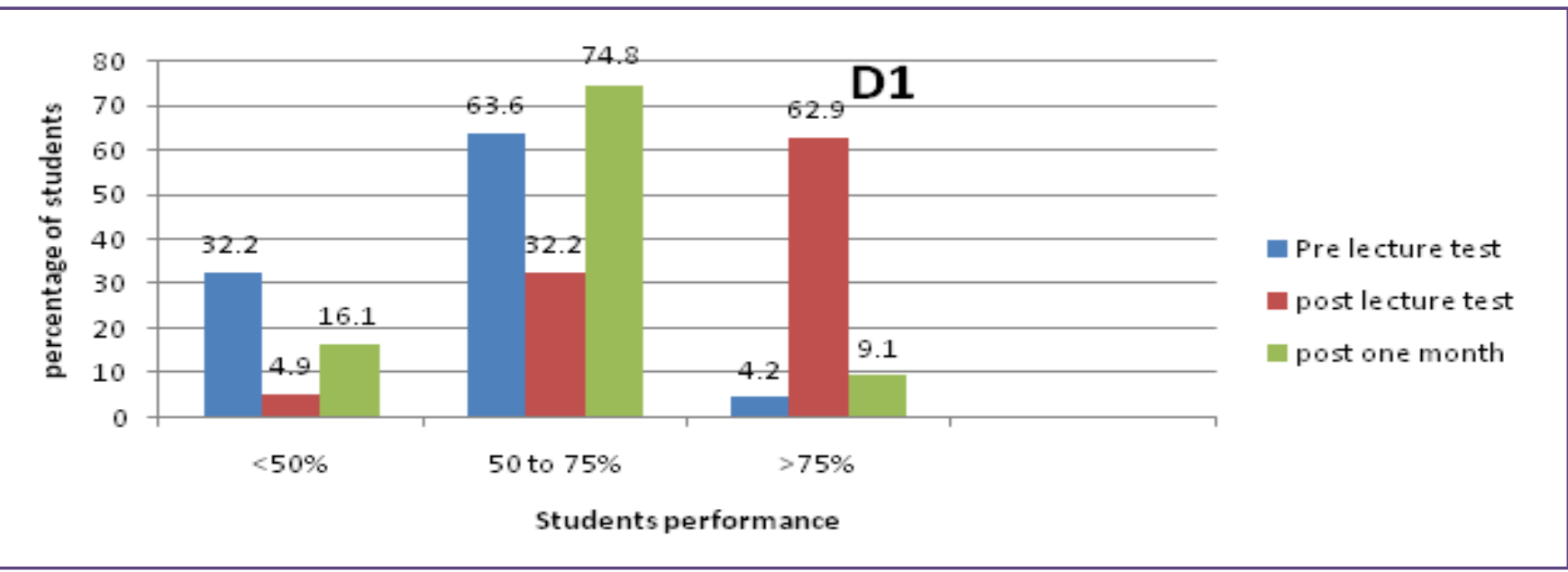

Fig. 2: Assessment of the Medical students' knowledge in pre lecture, post lecture,and post one month test in Domain(D1) "Existence of Biomedical waste disposal rules".

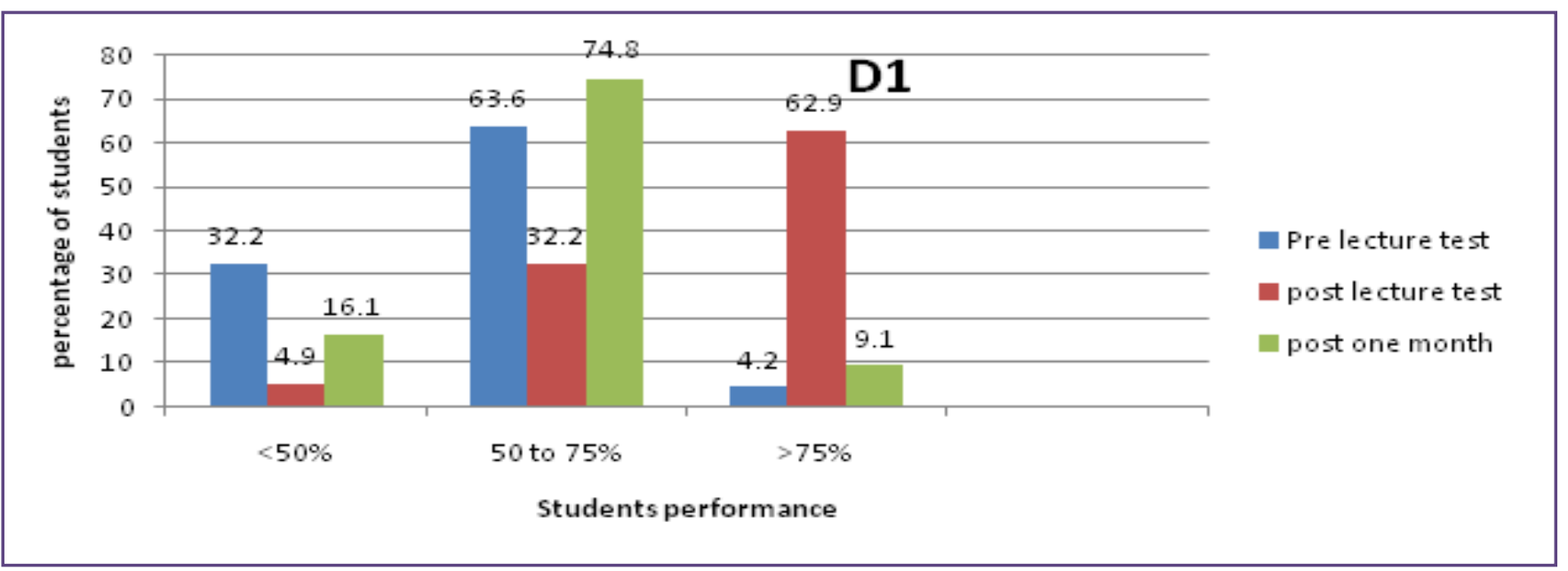

Fig. 3: Assessment of the Medical students' knowledge in pre lecture, post lecture testand post one month test in Domain "Categories of Biomedical waste" 


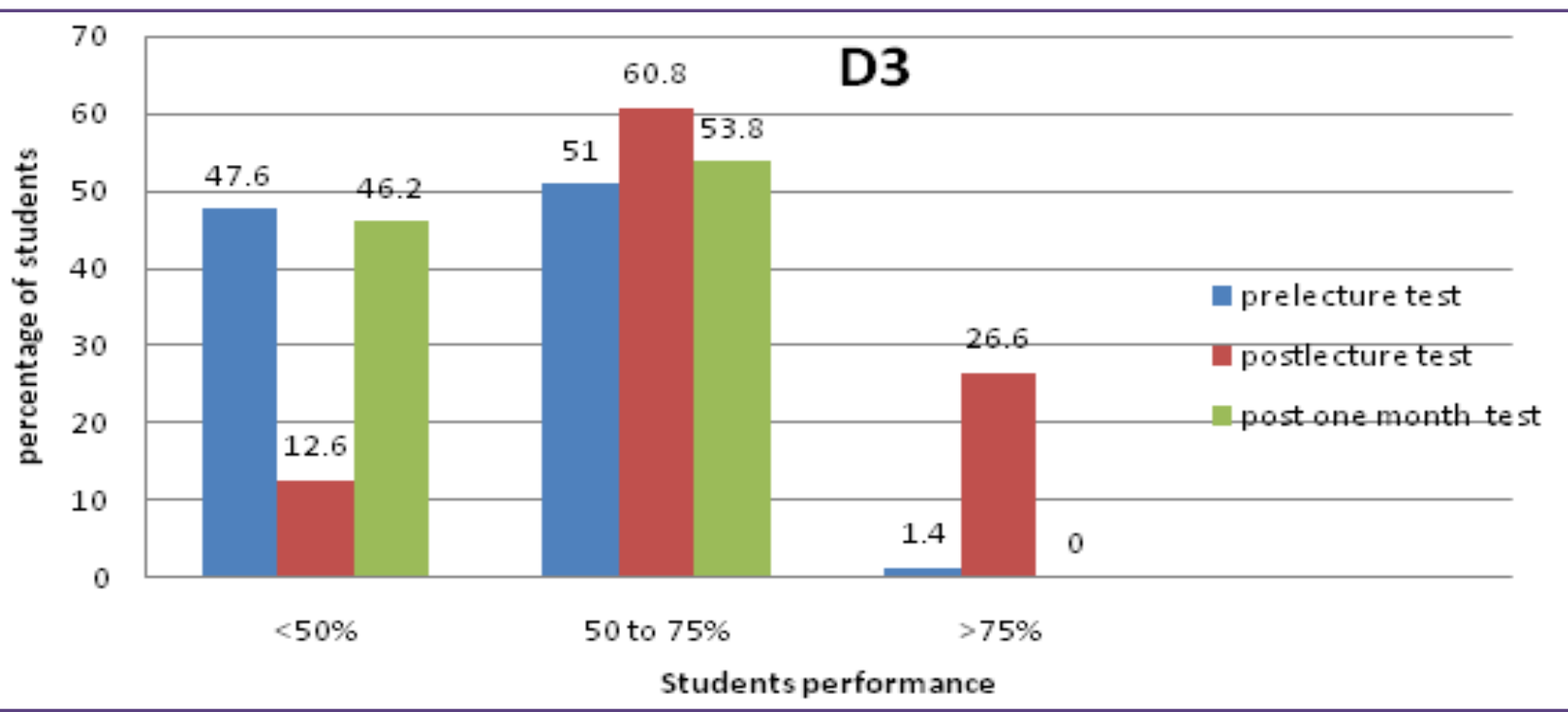

Fig. 4: Assessment of the Medical students' knowledge in pre lecture, post lecture test and post one month in Domain(D3) "Different colour codes".

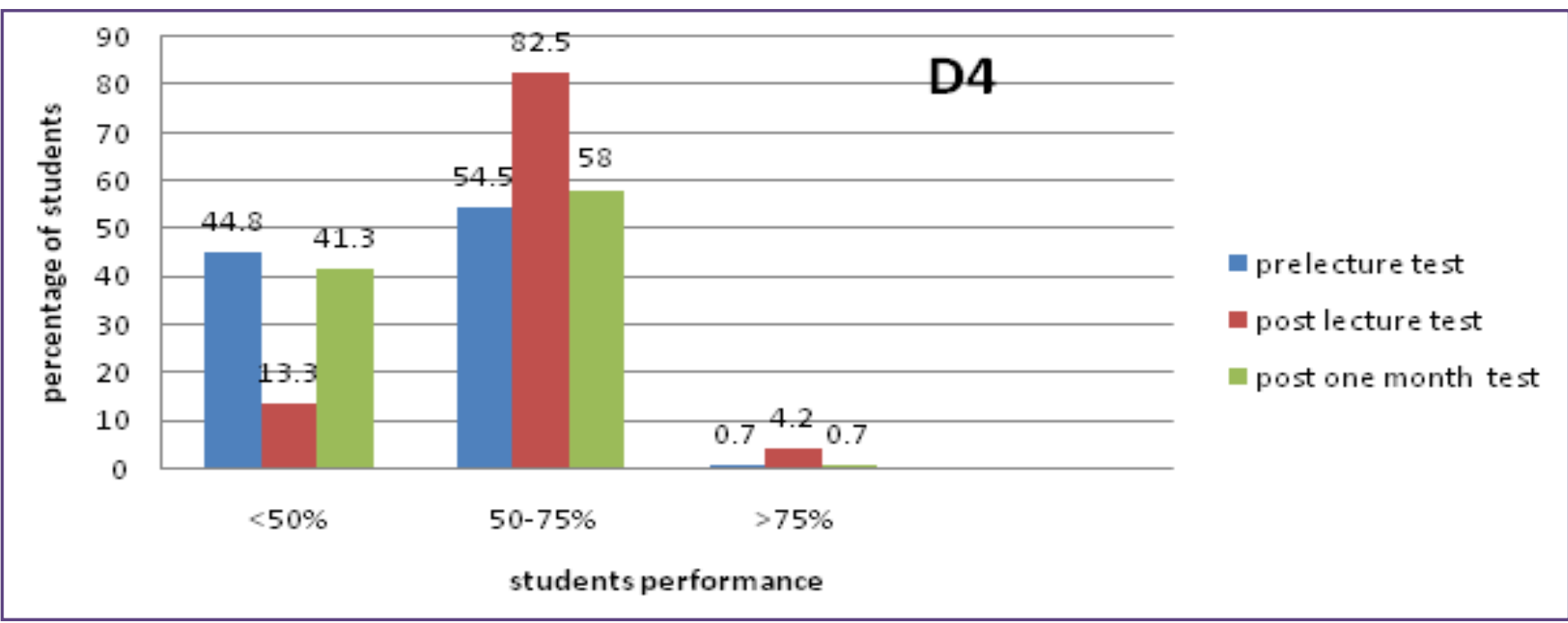

Fig. 5: Assessment of the Medical students' knowledge in pre lecture, post lecture and post one month test in Domain(D4) "Waste disposal methods".

\section{Discussion}

Although there is an increased global awareness among health professionals about the hazards and also appropriate management techniques, the level of awareness in India is found to be below par. Adequate knowledge about the health hazard of hospital waste, proper technique, and methods of handling the waste could go a long way toward the safe disposal of hazardous hospital waste and protect the community. ${ }^{[2]}$

The problem of bio-medical waste disposal in the hospitals and other healthcare establishments has become an issue of increasing concern, prompting hospital administration to seek new ways of scientific, safe and cost effective management of the waste, and keeping their personnel informed about the advances in this area. ${ }^{[3,4]}$

Different studies highlight the urgent need for greater awareness and commitments at policy and programme levels for capacity building and resource investments in BMWM.The last decade witnessed a significant increase of public concern regarding Medical Waste disposal. This was fuelled by reports of 'beach washing" of medical waste on the coasts of Florida and Gulf, and the "recycling" of disposable articles in developing countries. ${ }^{[5]}$ The reports 
and figures available from developed countries indicate that approximately $1-5 \mathrm{~kg}$ of waste is generated per bed per day, with substantial inter country and inter specialty differences. The data available from developing countries also indicate that the range is essentially similar but the figures are on a lower side with 1-2 $\mathrm{kg}$ per day per bed. ${ }^{[6]} \mathrm{In}$ India, it is estimated to be $2.0 \mathrm{~kg} / \mathrm{bed} /$ day. ${ }^{[7]} \mathrm{The}$ concern regarding the medical waste is mainly due to the presence of pathogenic organisms and organic substances in hospital solid wastes in significantly high concentrations. The substantial number of organisms of human origin in solid waste suggests the presence of virulent strains of viruses and pathogenic bacteria in undetected numbers. ${ }^{[8]}$ Therefore, improper handling of solid waste in the hospital may increase the airborne pathogenic bacteria, which could adversely affect the hospital environment and community at large. ${ }^{[9]}$ Improper Hospital Waste Management has serious impact on our environment. Apart from risk of water, air \& soil pollution, it has considerable impact on human health due to aesthetic effects. ${ }^{[10,11]}$ Government of India reacted towards the global concern and notified the Biomedical waste management rules,1998 (Ministry Of Environment \& Forests, Notification, New Delhi 20th July 1998). These rules have been framed in exercise of powers conferred by Sections 6,8 and 25 of Environment (Protection) Act 1986. This is applicable to every hospital and nursing home, veterinary institutions, animal house or slaughterhouses, which generate, Biomedical waste within a time frame.These rules were modified in 2011,2015 and latest in 2016. ${ }^{[12]}$

The Objectives of BMW management are mainly to reduce waste generation,Efficient collection, handling and disposal of waste in such a way that it does not spread infection, Provides safety to employees working in the system andEnsure cost effectiveness by avoiding penalties and fines imposed by regulatory authorities. Accordingly, waste is required to be treated and disposed off in accordance with schedules prescribed. The basic elements is to recognize the waste, identify where waste is generated and determine the cause of generation, plan the disposal of the waste in a scientific manner so as to render it environmentally non-hazardous and eliminate the source of infection. ${ }^{[9]}$

According to a World Health Organization (WHO) report, around $85 \%$ of the hospital wasted are actually nonhazardous, $10 \%$ are infectious (hence, hazardous), and the remaining $5 \%$ are non infectious but hazardous (chemical), pharmaceutical and radioactive. ${ }^{[13]}$ Bio-medical waste differs from hospital waste in the sense that it is "any solid, fluid or liquid waste, including its container and any intermediate product. These products could be generated during the diagnosis, treatment and immunization of human beings or animals, in research pertaining there to, or in the production or testing of biological and the animal waste from slaughter houses or any other like establishments. ${ }^{[13]}$

According to the WHO, the global life expectancy is increasing year after year. However, deaths due to infectious disease are increasing.One of major causes for the increase in infectious diseases is improper biomedical waste management.List of infections and diseases documented to have spread through biomedical waste include Tuberculosis, pneumonia, diarrhoeal diseases, tetanus are other common diseases spread due to improper waste management. ${ }^{[14]}$

Occupational health concerns exist for janitorial and laundry workers, nursing, emergency medical personnel, and refuse workers, injuries from sharps and to harmful chemical waste and radioactive waste also cause health hazards to the employees in institutions generating biomedical waste. Proper management can solve the problem of occupational hazards to a large extent. ${ }^{[14]}$

The general public's health can also be adversely affected by bio-medical waste. Improper practices such as dumping of bio-medical waste in municipal dustbins, or spaces, water bodies etc., leads to the spread of diseases. Emissions from incinerator and open burning also leads to exposure to harmful gases which can cause respiratory diseases and cancer. Plastic waste can choke animals, which scavenge on dumped waste. Injuries from sharps are common feature-affecting animals and rag pickers. Harm chemicals such as dioxins and furans can cause serious health hazards to animal and birds. Certain heavy metals can affect the reproductive health of the animals. ${ }^{[14,15]}$

Bio-Medical Waste Management Rules, 2016, published in the Official Gazette apply to all persons who generate, collect, receive, store, transport, treat, dispose, or handle bio medical waste in any form including hospitals, nursing homes, clinics, dispensaries, veterinary institutions, animal houses, pathological laboratories, blood banks, Ayushhospitals, clinical establishments, research or educational institutions, health camps, medical or surgical camps, vaccination camps, blood donation camps, first aid rooms of schools, forensic laboratories and research labs. ${ }^{[16]}$ A gap between knowledge and actual practice regarding Hospital Waste Management was highlighted in the perception of the hospital staff in a study carried out in 
Ujjain. The participants suggested organisational changes, training and monitoring to address this problem. This is relevant not merely to micro system studied but to other institutions in similar settings. ${ }^{[17]}$

Several studies have been conducted in primary, secondary, tertiary health centres of private and governments institutes in India in urban and rural areas and assessed for the state of BMWM. Multivariate analysis indicated that charts at point of waste generation , availability of designed person, appropriate containers and bags, availability of functional needle destroyers , availability of personal protective gears, segregation of waste at point of generation and log book maintenance were independently associated with better BMWM system in health facilities. This was true for both rural /urban, public/ private facilities. ${ }^{[18]}$

The present study was conducted on Second year MBBS students. The study showed that the baseline knowledge of second MBBS students on Biomedical waste management, which was not adequate, improved significantly after the interventional strategy, i.e, the lecture delivered by one of the investigators of the study. However the knowledge levels did not sustain after one month, though they were still more than the original baseline levels as was proved by using statistical tests. This indicates that further intermittent sensitization is necessary for sustaining knowledge.

After reviewing the literature, not many studies are published regarding knowledge of awareness regarding BMWM among medical students who are one of the stakeholders for BMWM which highlights the importance of this study and need of hour for early sensitization for BMWM among medical students. As present MBBS students are tomorrow's doctors, early sensitisation and repeated revision of this important topic for MBBS students will be useful in improving the awareness of biomedical waste disposal management in future Doctors and will prove beneficial for the society at large.

\section{Conclusions}

Early sensitisation of MBBS students will be useful in improving the awareness of biomedical waste disposal management. Further repetition will be useful for the knowledge levels to sustain As Doctors have to play a role as a leader in a health care team,awareness of this important subject will be beneficial to the society at large.

\section{References}

1. Gopalakrishnan S,.Murali R. Hospital Management Care. Indian J of Community Health 1999;4: 91-4.
2. Shivalli S, Sanklapur V. Healthcare Waste Management:Qualitative and Quantitative Appraisal of Nurses in a Tertiary Care Hospital of India. The Scientific World J. Vol 2014, Article ID 935101, http://dx.doi. org/10.1155/2014/935101.

3. Mathur P, Patan S, Anand S, Shobhawat A .Need of Biomedical Waste Management System in Hospitals - An Emerging issue - A Review Department of Environmental Science.Curr World environment 2012; 7:117-124.

4. INCLEN Program Evaluation network study group, New Delhi, India Biomedical waste management; situational analysis and predictors of performances in 25 districts across 20 Indian states. Indian J Med Res, 2014 January:139; 141-153.

5. Ruff GG Jr. Environmental laws in health care. Hosp Mater Manage Q, 1992 Nov; 14 (2) : 28-39.

6. Report of High Power Committee on Urban- Solid Waste Management, Planning Commission, Govt. of India, Hospital waste management 1995; 35-47.

7. Archisman M, Gupta MK, Shivali S, Mishra CP,Mohapatra SC. Biomedical Waste Management Practices of Doctors:An Online Snapshot. Nat J of Community Medicine. April-June 2012;3(2):227-231.

8. Wallace LP, Zaltzman R, Burchinal IC, Where solid waste comes from; where it goes, Modem hospitals 1972; 121(3): 92-5.

9. Li China-shan, Jeng Fu-Tien. Physical and chemical composition of hospital waste. Infect Control Hosp. Epidemiol, 1993; 14:145-150.

10. Rutala WA, Mayhall CG. Medical Waste. Infection control and hospital epidemiology. 1992; 13:38-48. DOI 10.1086/501924.

11. Satpathy S, Pandhi RK, Manual for Hospital waste management at AIIMS Hospital, 1998, New Delhi.

12. Ministry of Environment and Forests, Government of India. Draft Bio-medical Waste ( Management and Handling ) Rules, 2011.

13. Yadav M. Hospital Waste-A Major Problem. JK-Practitioner 2001;8(4):276.

14. Babu R, Parande AK, Rajalakshmi R, Suriyakala P, Volga M. Management of Biomedical Waste in India and Other Countries: A review. J Int Environmental Application and Science. 2009;4(1):65-78.

15. Garg KN, Singh S, Gupta K, Raj N. An Insight on Biomedical Waste Management $-\mathrm{A}$ Review. Inter $\mathrm{J}$ of Bio and Pharm Res. 2015;6(2):144-9.

16. Government Of India Ministry Of Environment, Forest And Climate. Gazette of India, Extraordinary, Part II, Section 3, Sub-section (i). 2016 March 28. 
17. Bansal M, Mishra A, Gautam P, Changulani R, Srivastava D, Gaur N .Biomedical waste management: Awareness and practices in a district of Madhya Pradesh.Nat $\mathrm{J}$ of Community medicine. 2011;2(3):452.
18. Joshi SC, Diwan V, Tamhankar AJ, Joshi R, Shah H, Sharma $\mathrm{N}$ et al; Staff perception on biomedical or Health care waste management : a Qualitative study in a rural Tertiary care Hospital in India. PloS one 10950:e0128383. doi 10.1371/ journal.pone. 0128383

\section{*Corresponding author:}

Dr Dhananjay Shrikant Kotasthane, Department of Pathology, Mahatma Gandhi Medical College and Research Institute, Pillaiyarkuppam, Pondicherry, India

Phone: +91 9092096244

Email: dskotasthane@gmail.com

Date of Submission : 03.01.2017

Date of Acceptance : 04.02.2017

Financial or other Competing Interests: None.

Date of Publication : 14.04.2017 